\title{
HERANÇA DA RESISTÊNCIA AO Papaya ringspot virus EM MELANCIA ${ }^{1}$
}

\author{
LINDOMAR MARIA DA SILVEIRA ${ }^{2 *}$, MANOEL ABILIO DE QUEIRÓZ ${ }^{3}$, JOSÉ ABÉRSIO DE ARAÚJO LIMA ${ }^{4}$, \\ GLAUBER HENRIQUE DE SOUSA NUNES ${ }^{2}$, ALINE KELLY QUEIROZ DO NASCIMENTO ${ }^{4}$, IZAIAS DA SILVA \\ LIMA NETO 5
}

RESUMO - Com o objetivo de estudar o controle genético da resistência a Papaya ringspot virus, type watermelon (PRSV-W) em melancia foram avaliadas a cultivar Crimson Sweet $(\mathrm{CS})\left(\mathrm{P}_{1}\right.$ - suscetível) e L26 proveniente de PI 244019 ( $\mathrm{P}_{2}$ - resistente), bem como as populações $\mathrm{F}_{1}, \mathrm{~F}_{2}, \mathrm{RC}_{11}$ e $\mathrm{RC}_{21}$, provenientes do cruzamento das duas linhas. As avaliações foram realizadas em casa de vegetação mediante inoculações artificiais com PRSV-W. Foi realizada avaliação sintomatológica através de escala de notas, bem como avaliação sorológica contra antissoro específico para PRSV-W através do teste ELISA indireto. As estimativas das variâncias das populações $\mathrm{P}_{1}, \mathrm{P}_{2}, \mathrm{~F}_{1}, \mathrm{~F}_{2}, \mathrm{RC}_{11}$ e $\mathrm{RC}_{21}$ foram utilizadas para obtenção das variâncias genética $\left(\sigma_{\mathrm{G}}^{2}\right)$, ambiental $\left(\sigma_{\mathrm{E}}^{2}\right)$, fenotípica $\left(\sigma_{\mathrm{F} 2}^{2}\right)$, aditiva $\left(\sigma_{\mathrm{A}}^{2}\right)$ e de dominância $\left(\sigma_{\mathrm{D}}^{2}\right)$ das herdabilidades no sentido amplo $\left(\mathrm{h}^{2}{ }_{\mathrm{a}}\right)$ e restrito $\left(\mathrm{h}_{\mathrm{r}}^{2}\right)$. A hipótese de herança monogênica foi testada sob diferentes graus médios de dominância presumido, bem como pelo método da máxima verossimilhança. A distribuição de frequência de plantas resistentes nas populações segregantes diferiu de uma distribuição baseada em herança monogênica para todos os graus médios de dominância presumidos, de modo que a hipótese de herança monogênica foi rejeitada mostrando que essa característica em L26 é controlada por mais de um gene maior com a presença de modificadores. O modelo aditivo-dominante foi adequado para explicar o tipo de ação gênica envolvida e os efeitos epistáticos não foram importantes na expressão da resistência. A estimativa do grau médio de dominância indicou efeito de dominância completa. E as herdabilidades, no sentido amplo, das duas variáveis analisadas foram intermediárias.

Palavras-chave: Citrullus lanatus. Herança. PRSV-W.

\section{INHERITANCE OF RESISTANCE TO Papaya ringspot virus IN WATERMELON}

\begin{abstract}
Aiming to study the genetic control of Papaya ringspot virus, type watermelon (PRSV-W) in watermelon, the cultivar Crimson Sweet $\left(\mathrm{P}_{1}\right.$ - susceptible) and L26 derived from PI 244019 (P2 - resistant), as well as the resulting populations $\mathrm{F}_{1}, \mathrm{~F}_{2}, \mathrm{RC}_{11}$ and $\mathrm{RC}_{21}$ of the cross of both lines were evaluated. The trials were carried out in a greenhouse, and the evaluations were done using artificial inoculations with PRSV-W isolates. The seedling symptoms were recorded using a graded scale, and the serological evaluation was done with specific antiserum using indirect ELISA. The estimated variances of the populations were used to obtain the genetic $\left(\sigma_{\mathrm{G}}^{2}\right)$, the environmental $\left(\sigma_{\mathrm{E}}^{2}\right)$, phenotypic $\left(\sigma_{\mathrm{F} 2}^{2}\right)$, additive $\left(\sigma_{\mathrm{A}}^{2}\right)$ and dominance $\left(\sigma_{\mathrm{D}}^{2}\right)$ variances as well as the broad $\left(\mathrm{h}_{\mathrm{a}}^{2}\right)$ and narrow sense $\left(\mathrm{h}_{\mathrm{r}}^{2}\right)$ heritabilities. The hypothesis of monogenic inheritance was tested under different presumed average degrees of dominance as well as using the maximum likelihood. The distribution of resistant plants in the segregating populations was different from a distribution based on monogenic inheritance for all presumed average degrees of dominance, therefore, the hypothesis of monogenic inheritance was rejected indicating that this character in the line L26 is controlled by more than one major gene with the presence of modifiers. The additive-dominant model was adequate to explain the type of gene action involved, and the epistatic effects were not important in the expression of the resistance. The estimated average degree of dominance indicated complete dominance. The broad sense heritabilities for the two variables analyzed were intermediate.
\end{abstract}

Keywords: Citrullus lanatus. Genetic control. PRSV-W.

\footnotetext{
*Autor para correspondência

${ }^{1}$ Recebido para publicação em 28/09/2014; aceito em 30/04/2015.

${ }^{2}$ UFERSA - Depto. de Ciências Vegetais, Mossoró (RN). lindomarmaria@ufersa.edu.br.

${ }^{3}$ UNEB - Depto. de Tecnologia e Ciências Sociais, Juazeiro (BA).

${ }^{4}$ UFC - Laboratório de Virologia Vegetal, Departamento de Fitotecnia, Campus do Pici Fortaleza (CE).

${ }^{5}$ UNIVASF - Petrolina (PE).
} 


\section{INTRODUÇ̃̃̃O}

A quase totalidade das cultivares de melancia [Citrullus lanatus (Thunb.) Matsum. \& Nakai] disponíveis no comércio brasileiro foram importadas de países como Japão e Estados Unidos, de modo que quando cultivadas no Brasil, em especial na região Nordeste, apresentaram suscetibilidade a diferentes pragas e doenças (COSTA; PINTO, 1977).

$\mathrm{Na}$ referida região brasileira os vírus da família Potyviridae, gênero Potyvirus (Papaya ringspot virus, type watermelon - PRSV-W), (Watermelon mosaic virus - WMV) e (Zucchini yellow mosaic virus - ZYMV) - constituem fator limitante ao cultivo da melancia, ocasionando grandes perdas econômicas. Em virtude da dificuldade de seu controle através do uso de produtos químicos, a resistência genética pode se constituir em um método eficiente para reduzir danos ocasionados pelos supracitados vírus.

Fontes de resistência a esses vírus têm sido identificadas em várias espécies de cucurbitáceas (OLIVEIRA et al., 2002; STRANGE et al., 2002; SVOBODA; POLÁK, 2004; VIEIRA et al., 2010). Porém, o controle genético da resistência a PRSVW, WMV e ZYMV pode variar de acordo com a fonte, mesmo para uma mesma espécie viral (WANG et al., 1984; PROVVIDENTI, 1991; GILBERT et al., 1994; WAI; GRUMET, 1995; DANINPOLEG et al., 1997; SITOLIN et al., 2000; XU et al., 2004; BESERRA JÚNIOR et al., 2006; BESERRA JÚNIOR et al., 2007). Dessa forma, o conhecimento da herança genética da resistência pode permitir o desenvolvimento de estratégias que possibilitem o uso de fontes de resistência em programas de melhoramento de forma mais rápida e eficiente. Assim, devido a variação que ocorre em cucurbitáceas com a herança da resistência aos citados vírus há necessidade de se investigar o controle genético da resistência nas fontes que se pretende utilizar, não podendo se extrapolar resultados obtidos para outras fontes.

O presente trabalho teve como objetivo estudar o controle genético da resistência ao PRSV-W na linha de melancia L26, do programa de melhoramento de melancia para o Nordeste Brasileiro desenvolvido pela Embrapa Semiárido/UNEB.

\section{MATERIAL E MÉTODOS}

No Campo Experimental do Departamento de Tecnologia e Ciências Sociais da Universidade do Estado da Bahia (UNEB/DTCS) foi realizado o cruzamento da cultivar Crimson Sweet (CS) ( $\mathrm{P}_{1}$ - suscetível) e a linha L26 $\left(\mathrm{P}_{2}\right.$. resistente), oriunda de autofecundações do acesso PI 244019 e obtidas as populações $\mathrm{F}_{1}, \mathrm{~F}_{2}, \mathrm{RC}_{11}$ e $\mathrm{RC}_{12}$ por meio de cruzamentos controlados no primeiro e segundo semestres de
2006. Na ocasião, foram utilizadas parcelas compostas por 15 a 20 plantas, dispostas em fileiras contínuas e alocadas uma ao lado da outra para facilitar a transferência de pólen.

Os tratos culturais foram aqueles utilizados normalmente para a cultura da melancia. Durante a etapa de campo não foi realizado o controle de afídeos, evitando, assim, a eliminação de possíveis vetores naturais de vírus do gênero Potyvirus.

A avaliação em casa de vegetação, no Laboratório de Virologia Vegetal da Universidade Federal do Ceará (LabVVe/UFC), foi realizada no primeiro semestre de 2008, com amostras compostas das populações $\mathrm{F}_{1} \mathrm{~s}, \mathrm{~F}_{2} \mathrm{~s}, \mathrm{RC}_{11} \mathrm{~s}$ e $\mathrm{RC}_{21} \mathrm{~s}$, sendo a amostra composta de número igual de sementes das progênies obtidas em cada população.

Foi utilizado delineamento em blocos casualizados com quatro repetições. Cada bloco foi constituído de 15 plantas da população $\mathrm{P}_{1}(\mathrm{CS}), 15$ plantas de $\mathrm{P}_{2}$ (L26), 21 plantas de $\mathrm{F}_{1}$ (CS x L26), 63 plantas de $F_{2}\left(F_{1} \times F_{1}\right), 35$ plantas de $R_{11}\left(F_{1} \times C S\right)$ e 35 plantas de $\mathrm{RC}_{21}\left(\mathrm{~F}_{1} \times \mathrm{L} 26\right)$, de forma que no experimento foram utilizadas 60 plantas para $P_{1}, 60$ plantas para $P_{2}, 84$ plantas para $F_{1}, 252$ plantas para $F_{2}, 140$ plantas para $\mathrm{RC}_{11}$ e 140 plantas para $\mathrm{RC}_{21}$. Sementes das populações foram semeadas em vasos contendo substrato composto de solo e esterco de curral na proporção $2: 1$, respectivamente. O substrato foi esterilizado em autoclave a uma temperatura de $120{ }^{\circ} \mathrm{C}$ por duas horas. $\mathrm{E}$ foram cultivadas quatro plantas por vaso.

Para inoculação foi utilizado como inóculo o isolado do PRSV-W obtido em campo de produção de melão (Cucumis melo L) e/ou melancia do Estado do Ceará, o qual é mantido no Banco Ativo de Vírus do LabVVeg/UFC (OLIVEIRA et al., 2000).

A primeira inoculação foi realizada na fase inicial de desenvolvimento das plantas, antes do surgimento da primeira folha definitiva, cerca de oito dias após a semeadura. Utilizou-se como fonte de inóculo extrato de plantas de abobrinha (Cucurbita pepo L.) cv. Caserta sistemicamente infectadas por PRSV-W. As amostras foliares para realização do teste enzyme-linked immunosorbent assay (ELISA) indireto foram coletadas em vários pontos da planta. Os extratos foram preparados na presença de solução tampão (Fosfato de potássio 0,5 M e pH 7,5), através da maceração de tecido foliar infectado na proporção de $1,0 \mathrm{~g}$ de tecido foliar infectado para $2,0 \mathrm{ml}$ de solução. Dez dias após a primeira inoculação foi realizada uma avaliação sintomatológica de acordo com a escala de notas previamente estabelecida como segue: 1 - Sem sintomas; 2 - Mosaico com ou sem clareamento das nervuras e/ou enrolamento do limbo; 3 - Mosaico, enrolamento do limbo, necrose das brotações e/ou bolhosidade; e 4 - Mosaico, enrolamento do limbo, necrose das brotações, bolhosidade e/ou deformação severa.

De acordo com Almeida (2001), uma planta foi considerada de resultado negativo em ELISA 
quando apresentou absorbância inferior a duas vezes a média das absorbâncias das plantas sadias (plantas sem inoculação utilizadas como controle) mais duas vezes o desvio padrão das leituras para as plantas sadias. As plantas que não apresentaram sintomas e foram negativas em ELISA foram submetidas a uma segunda inoculação para diminuir a possibilidade de escape. Vinte dias após a segunda inoculação foi realizada nova avaliação sintomatológica seguida de sorologia por ELISA indireto para confirmar a resistência das plantas que não apresentaram sintomas e foram negativas no primeiro teste.

Considerando que algumas plantas podem apresentar resistência do tipo tolerância, característica nota dos sintomas (NS) e sorologia em ELISA indireto (absorbância) (ABS), foram avaliadas as variâncias das populações $\mathrm{P}_{1}, \mathrm{P}_{2}, \mathrm{~F}_{1}, \mathrm{~F}_{2}, \mathrm{RC}_{11}$ e $\mathrm{RC}_{21}$ e utilizadas para obtenção de variâncias genéticas $\left(\sigma_{\mathrm{G}}^{2}\right)$, ambiental $\left(\sigma_{\mathrm{E}}^{2}\right)$, fenotípica $\left(\sigma_{\mathrm{F} 2}^{2}\right)$, aditiva $\left(\sigma_{\mathrm{A}}^{2}\right)$ e de dominância $\left(\sigma_{\mathrm{D}}^{2}\right)$, das herdabilidades no sentido amplo $\left(\mathrm{h}_{\mathrm{a}}^{2}\right)$ e restrito $\left(\mathrm{h}_{\mathrm{r}}^{2}\right)$

Os efeitos aditivos [a] e não aditivos [d] do(s) gene(s) que controla $(\mathrm{m})$ o caráter foram estimados a partir das médias das gerações pelo método dos quadrados mínimos ponderados (CRUZ et al., 2004; RAMALHO et al., 2011). As análises foram realizadas utilizando o programa estatístico Genes (CRUZ, 2006). E os dados foram usados para testar a hipótese de herança monogênica sob diferentes graus médios de dominância presumidos, como descrito por Oliveira et al. (2003).

Também foi testada a hipótese de herança monogênica e/ou a presença de loci poligênicos ou modificadores afetando o caráter através de uma metodologia alternativa proposta por Silva (2003), utilizando-se estimadores de máxima verossimilhança. Essa metodologia trabalha com modelos em que o modelo mais geral considera a presença de um gene de efeito maior mais poligenes com efeitos aditivos e de dominância, além de variâncias ambientais iguais em todas as gerações. Também foram admitidos genes independentes, de efeito maior, bem como poligenes, sendo que a partir das funções de verossimilhança para cada modelo foi possível compor testes de interesse considerando várias hipóteses. Para realização dos testes fora utilizado o software estatístico Monogen 1.0 desenvolvido por Silva (2003).

\section{RESULTADOS E DISCUSSÃO}

Foram observadas plantas com nota de sintomas (NS) superiores a 1,0 (sem sintomas) em $\mathrm{P}_{1}$ (Crimson Sweet - CS) e $\mathrm{P}_{2}$, (Linha 26 - L26) embora em L26 tenha ocorrido apenas uma planta com nota superior a 1,0 (Figura 1). Houve maior segregação de NS para o genitor suscetível (CS) (Figura 1). Quando foi considerada a absorbância (ABS) os resultados não se repetiram, sendo que L26 não apresentou plantas suscetíveis (Figura 1).

Outrossim, foram observadas que a distribuição de frequência de fenótipos nas populações $F_{1} F_{2}$ (Figura 1) se aproxima da distribuição baseada em herança monogênica recessiva. Por outro lado, a distribuição de frequência para $\mathrm{RC}_{11}$ e $\mathrm{RC}_{21}$ difere daquela baseada em herança monogênica, permitindo inferir que a herança da resistência ao PRSV-W em L26 seja oligo ou poligênica.

Independente da variável considerada não ocorreu diferença no resultado final. A ocorrência de plantas resistentes em CS, mesmo quando considerada a ABS, poderia ser considerada escape em razão do pequeno número de plantas resistentes nessa população. Porém, as plantas foram submetidas a duas inoculações e as testemunhas utilizadas nestas foram todas suscetíveis quando avaliadas por ELISA indireto (dados não apresentados). Dessa forma, os dados observados permitem inferir sobre a possibilidade de ocorrência de genes modificadores, corroborando com a hipótese de herança oligo ou poligênica, uma vez que se a resistência ao PRSV-W fosse controlada por apenas um gene recessivo presente em L26 não seria possível a ocorrência de plantas resistentes em CS.

Vale salientar que a expressão de sintomas ocasionados pela infecção por vírus é bastante influenciada pelas condições ambientais e pelo hospedeiro infectado. Além disso, alguns genótipos podem se mostrar tolerantes e não expressarem sintomas quando infectados (SHUKLA; WARD; BRUNT, 1994). Dessa forma, é importante o uso da sorologia nas avaliações de resistência a vírus, uma vez que estudos baseados apenas em sintomatologia, mesmo que em alguns casos, como no presente trabalho, não interfira no resultado final pode atrapalhar na seleção de genótipos resistentes.

As estimativas de $\chi^{2}$ referentes ao teste de herança monogênica foram significativas $(\mathrm{P} \leq 0,05)$ para todos os graus médios de dominância presumidos, nas duas variáveis, levando a rejeição da hipótese de herança monogênica e indicando ser a resistência a PRSV-W controlada por mais de um gene (Figura 2). Oliveira et al. (2003) encontraram resultado semelhante ao estudar a resistência a PRSV-W em melancia e em Cucurbita moschata Poir, relatando a herança a PRSV-W como sendo controlada provavelmente por dois ou três locos em melancia e por mais de um loco em C. moschata, com ação predominantemente aditiva nos dois casos. Para resistência a PRSV-W em Cucumis melo L. e Cucumis metuliferus E. Mey foi relatada a herança da resistência como sendo monogênica dominante (PROVVIDENTI; ROBINSON, 1977; WEBB, 1979), enquanto que para Cucumis sativum L. a herança foi relatada como monogênica recessiva (WANG et al., 1984). Dessa forma, evidencia-se a necessidade de investigar o tipo de herança nas fontes que se deseja utilizar em programas de melhora- 
mento, uma vez que os resultados já encontrados não podem ser extrapolados, visto que o controle genético da característica de resistência pode variar de acordo com o genótipo que apresenta esta resistência.

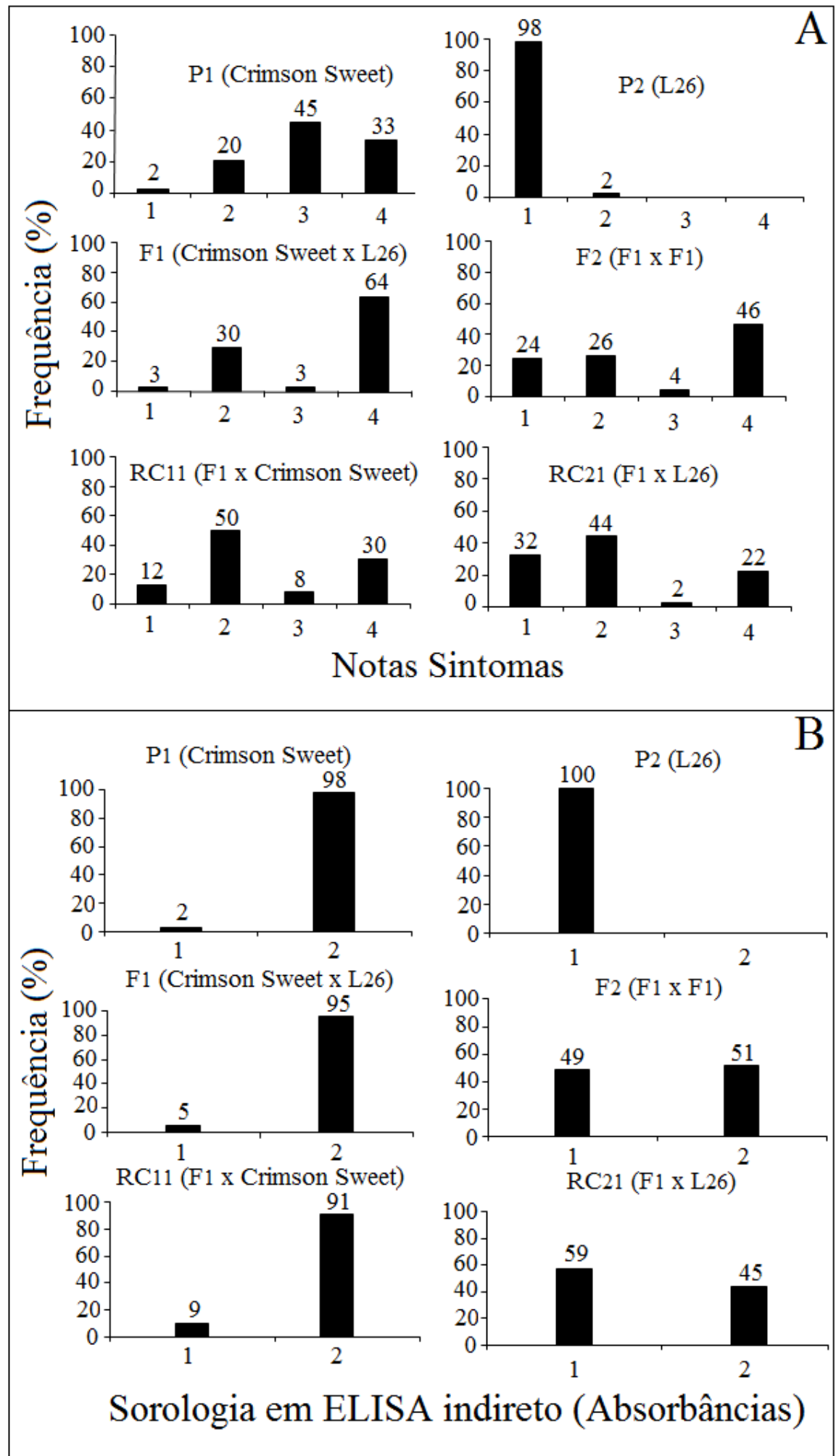

Figura 1. Distribuição de frequências para nota de sintomas (A) e resistente sorologia em ELISA indireto (B) dos parentais Crimson Sweet e Linha 26 e das gerações $\mathrm{F}_{1}, \mathrm{~F}_{2}, \mathrm{RC}_{11}$ e $\mathrm{RC}_{21}$ inoculadas com Papaya ringspot virus type watermelon (PRSV-W). UFERSA, Mossoró (RN), 2008. 
O valor de qui-quadrado $\left(\chi^{2}\right)$ estimado entre as médias esperadas e observadas não foi significativo para nenhuma das variáveis consideradas (Tabela 1), indicando que o modelo aditivo-dominante é adequado para explicar o controle da resistência em L26, não sendo necessário a inclusão de interações epistáticas no modelo. A epistasia é um fenômeno genético resultante da interação de alelos pertencentes a locos diferentes e sua presença no controle genético de caracteres tem como grande implicação a obtenção de estimativas de variâncias aditiva e de dominância viesadas (BERNARDO, 2000). Por outro lado, a ausência da epistasia é um aspecto positivo do ponto de vista pragmático nos programas de melhoramento genético de plantas, uma vez que facilita o trabalho do melhorista no processo seletivo. Com efeito, métodos simples, como o retrocruzamento, permitirão a introgressão dos alelos que conferem a resistência em cultivares com background relacionados a melhor qualidade do fruto como aqueles do tipo Crimson Sweet. Após a introgressão, linhagens resistentes devem ser obtidas por autofecundações sucessivas. Beserra Júnior et al. (2006) obtiveram linhagens resistentes aos vírus Watermelon mosaic virus e ao
Papaya ringspot virus a partir de cruzamentos entre Crimson Sweet e PI 595201, seguidos de retrocruzamentos para Crimson Sweet.

Apesar do componente aditivo [a] ter sido menor que o componente não aditivo [d] em NS e em ABS, e o [a] ter sido maior que o [d], os valores dos componentes foram aproximados nas duas variáveis. Por outro lado, as estimativas do GMD apresentaram variação entre as variáveis, consideradas superiores à unidade, indicando predominância de efeitos não aditivos no controle do caráter (Tabela 1). Quando as estimativas de GMD são superiores à unidade é um indicativo de sobredominância no controle genético do caractere. Nesta situação é sugerido desenvolver programas para a exploração de vigor de híbrido. As médias de $\mathrm{F}_{1}$ nas duas variáveis se aproximam de $\mathrm{CS}$, indicando que existe dominância dos alelos que conferem suscetibilidade em relação aos alelos que conferem resistência (Tabela 1). Neste caso, quando os alelos que conferem a resistência são recessivos o trabalho e o tempo para introgressão dos mesmos são maiores, uma vez que as autofecundações nas gerações ímpares se torna essencial para a sua manifestação fenotípica e a seleção.

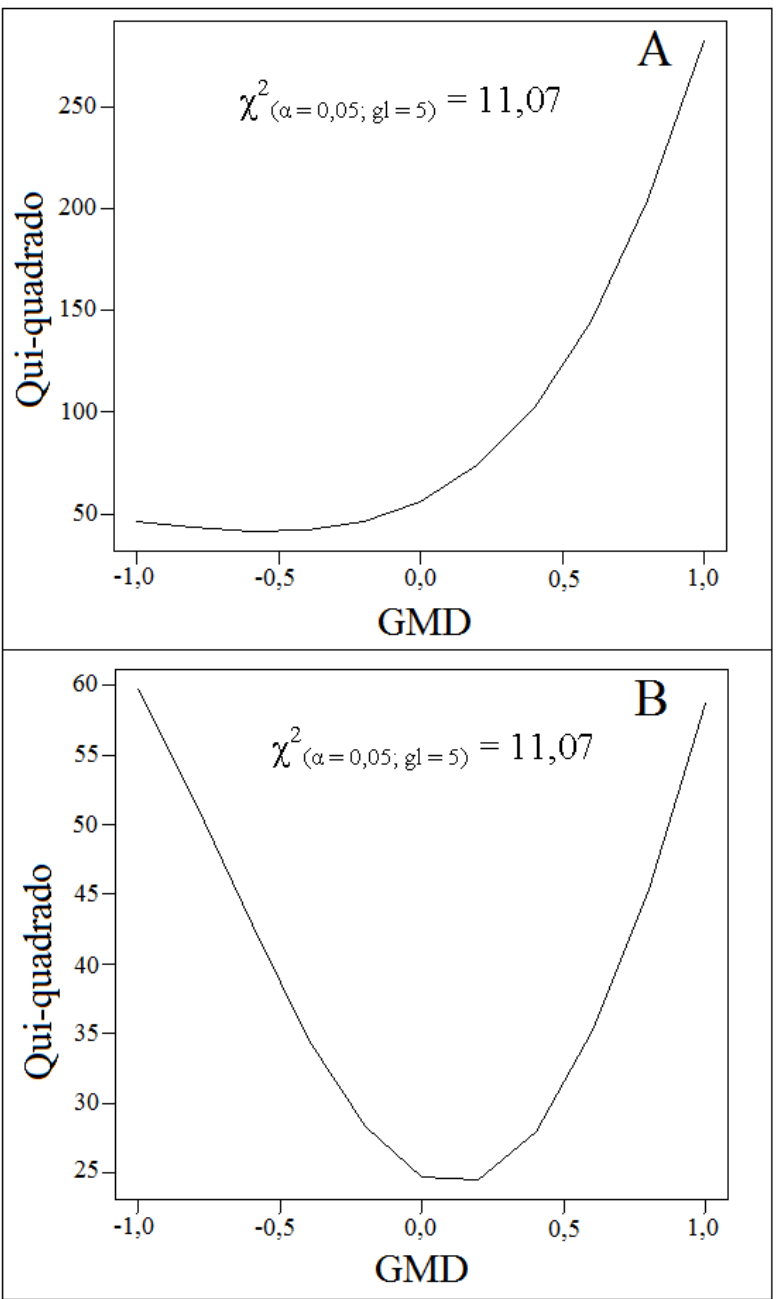

Figura 2. Teste de hipótese de herança monogênica sob diferentes graus médios de dominância presumidos para notas de sintomas (A) e sorologia em ELISA indireto (B) quanto a reação de populações de melancia (Citrullus spp.) ao Papaya ringspot virus type watermelon (PRSV-W). UFERSA, Mossoró (RN), 2008. 
Tabela 1. Médias dos parentais de melancia Crimson Sweet $\left(\mathrm{P}_{1}\right)$ (Citrullus lanatus) e Linha $26\left(\mathrm{P}_{2}\right)($ Citrullus lanatus var. citroides) e das gerações $\mathrm{F}_{1}, \mathrm{~F}_{2}, \mathrm{RC}_{11}, \mathrm{RC}_{21}$ e componentes de média quanto a reação ao Papaya ringspot virus type watermelon (PRSV-W). UFERSA, Mossoró (RN), 2008.

\begin{tabular}{lcc}
\hline & $\begin{array}{c}\text { Populações } \\
\text { de melancia (Citrullus spp.) }\end{array}$ & Médias \\
\cline { 2 - 3 } & Notas dos Sintomas & $\begin{array}{c}\text { Sorologia em ELISA indireto } \\
\text { (absorbância) }\end{array}$ \\
\hline $\mathrm{P}_{1}$ & 3,05 & 2,42 \\
$\mathrm{P}_{2}$ & 1,02 & 0,26 \\
$\mathrm{~F}_{1}$ & 3,31 & 2,89 \\
$\mathrm{~F}_{2}$ & 2,75 & 1,30 \\
$\mathrm{RC}_{11}$ (F1 x L26) & 2,55 & 1,92 \\
$\mathrm{RC}_{21}$ (F1 x CS) & 2,13 & 0,80 \\
\hline $\mathrm{m}$ & $1,9184 \pm 0,0298$ & $1,1991 \pm 0,0307$ \\
{$[\mathrm{a}]$} & $0,9183 \pm 0,0298$ & $0,9414 \pm 0,0307$ \\
{$[\mathrm{~d}]$} & $1,2196 \pm 0,0672$ & $0,7297 \pm 0,0691$ \\
$\chi^{2}$ & $0,1109^{\mathrm{NS}}$ & $0,6095^{\mathrm{NS}}$ \\
$\mathrm{GMD}$ & 1,1842 & 1,3932 \\
$n$ & 1,3 & 1,5 \\
\hline
\end{tabular}

$\mathrm{m}=$ média estimada dos parentais $\mathrm{P}_{1}$ e $\mathrm{P}_{2}$ [estimated average of parents $\mathrm{P}_{1}$ and $\mathrm{P}_{2}$ ]; [a] = efeito gênico aditivo [additive gene effect]; [d] = efeito gênico não aditivo [non-additive gene effect]; $\chi^{2}=$ Qui-quadrado para teste do Modelo aditivodominante [Chi-square test for the additive-dominant model]; GMD = Grau médio de dominância [Average degree of dominance]; $n=$ número de genes [number of genes]; e NS = não significativo [not significant].

As estimativas de herdabilidade, no sentido amplo, foram consideradas intermediárias para NS $(0,66)$ e ABS $(0,57)$ (Tabela 2$)$, indicando que a resistência a PRSV-W nas condições em que foram realizadas as avaliações foi bastante influenciada pelo ambiente. As estimativas de herdabilidade no sentido restrito também foram intermediárias para NS $(0,55)$ e elevada para ABS $(0,87)$ decorrente da estimativa negativa da variância de dominância. Mesmo que a resistência a PRSV-W sofra grande influência das condições ambientais esses valores de herdabilidade permitem inferir que podem ser obti- dos ganhos genéticos com a seleção de plantas resistentes em populações segregantes provenientes do cruzamento CS e L26 (Tabela 2). Azevedo et al. (2012), ao estudarem a resistência a PRSV-W na introdução de melancia PI 595201, encontraram valores elevados de herdabilidades no sentido amplo $(0,80)$ e restrito $(0,67)$. Ressalta-se que as estimativas de herdabilidades são intrínsecas às populações e às condições ambientais nas quais as mesmas foram obtidas. Com efeito, são comuns diferenças entre diferentes trabalhos.

Tabela 2. Variâncias dos parentais de melancia Crimson Sweet $\left(\mathrm{P}_{1}\right)$ (Citrullus lanatus) e Linha $26\left(\mathrm{P}_{2}\right)$ (Citrullus lanatus var. citroides) e das gerações $\mathrm{F}_{1}, \mathrm{~F}_{2}, \mathrm{RC}_{11}, \mathrm{RC}_{21}$ e herdabilidades no sentido amplo e restrito quanto a reação ao Papaya ringspot virus type watermelon (PRSV-W). UFERSA, Mossoró (RN), 2008.

\begin{tabular}{lcc}
\hline \multirow{2}{*}{$\begin{array}{c}\text { Populações de melancia (Citrullus } \\
\text { spp.) }\end{array}$} & \multicolumn{2}{c}{ Variâncias } \\
\cline { 2 - 3 } & Notas dos Sintomas & $\begin{array}{c}\text { Sorologia em ELISA } \\
\text { indireto (absorbância) }\end{array}$ \\
\hline $\mathrm{P}_{1}$ & 0,628 & 0,705 \\
$\mathrm{P}_{2}$ & 0,000 & 0,001 \\
$\mathrm{~F}_{1}$ & 0,999 & 1,233 \\
$\mathrm{~F}_{2}$ & 1,603 & 1,501 \\
$\mathrm{RC}_{11}$ (F1 x CS) & 1,107 & 0,929 \\
$\mathrm{RC}_{21}$ (F1 x L26) & 1,212 & 0,765 \\
\hline$\sigma^{2}{ }_{\mathrm{E}}$ & 1,6029 & 1,5005 \\
$\sigma^{2}{ }_{\mathrm{G}}$ & 1,0604 & 0,8540 \\
$\sigma^{2}{ }_{\mathrm{A}}$ & 0,8871 & 1,3070 \\
$\sigma_{\mathrm{D}}^{2}$ & 1,1773 & $-0,4529$ \\
$\mathrm{~h}^{2}$ & 55,3451 & 87,1073 \\
$\mathrm{~h}^{2}{ }_{\mathrm{a}}$ & 66,1581 & 56,9184 \\
\hline
\end{tabular}

$\sigma_{\mathrm{E}}^{2}=$ variância ambiental [environmental variance]; $\sigma_{\mathrm{G}}^{2}=$ variância genética [genetic variance]; $\sigma_{\mathrm{A}}^{2}=$ variância devida aos efeitos aditivos [variance due to additive effects]; $\sigma_{D}^{2}=$ variância devida aos efeitos de dominância [variância devida aos efeitos de dominância]; $\mathrm{h}_{\mathrm{r}}^{2}=$ herdabilidade no sentido restrito [narrow sense heritability]; $\mathrm{h}_{\mathrm{a}}{ }_{\mathrm{a}}=$ herdabilidade no sentido amplo [broad sense heritability]. 
Os dados obtidos com a análise das duas variáveis mostram que mesmo com variações nos parâmetros estimados, nas condições em que foram avaliadas, o resultado final não foi alterado. Dessa forma, pode ser utilizado qualquer uma das variáveis para estudo de herança da resistência a PRSV-W, desde que consideradas as condições em que os experimentos foram desenvolvidos, pois deve-se considerar que mudanças nas condições de avaliação podem alterar a expressão dos sintomas nas plantas suscetíveis, em especial mudanças na temperatura, a qual pode fazer com que os sintomas sejam mais ou menos severos a depender das condições em que as plantas são avaliadas, mesmo que o vírus se replique normalmente (BOYAN et al.,, 1992; LÊ ROMANCER; NEDELLEC, 1997).

Segundo Hull (2002), uma planta pode ser considerada imune a determinado vírus quando ele não se replica em protoplasto e em células intactas da planta, mesmo nas células inicialmente inoculadas. Embora não se tenha retroinoculado as plantas resistentes em uma cultivar suscetível para verificar a possibilidade de recuperação do vírus e não se tenha realizado nenhum teste ao nível de protoplastos as plantas foram testadas por ELISA indireto contra antissoro específico para PRSV-W e apresentaram resultado negativo, de forma que os dados permitem inferir que a resistência a PRSV-W em melancia apresentada por L26 pode ser do tipo imunidade ou extrema resistência, uma vez que as plantas avaliadas se comportaram como não hospedeiras, considerando a elevada sensibilidade do teste de ELISA para detectar a presença de vírus em tecidos vegetais. Por outro lado, é importante salientar que L26, quando na presença de um isolado de PRSV-W diferente do que foi utilizado no presente estudo, pode apresentar comportamento diferenciado, podendo ser tolerante ou até suscetível.

O teste de máxima verossimilhança (SILVA, 2003) trabalha com modelos hierarquizados, de forma que o contraste entre modelos pode levar a rejeição de um deles. Assim, o contraste do Modelo 1 com o Modelo 5 (Tabela 3), o qual confronta a existência de gene com efeito maior mais poligenes, com apenas poligenes, foi significativo para as duas variáveis avaliadas, evidenciando a existência de um gene de efeito maior. Da mesma forma comparando o Modelo 1 com o Modelo 7, que confronta a existência de um gene de efeito maior mais poligenes, com apenas gene de efeito maior, o contraste também foi significativo, havendo também evidência de efeitos poligênicos (Tabela 3 ).

Tabela 3. Testes de hipótese de herança monogênica por meio da função de máxima verossimilhança para notas de sintomas e sorologia em ELISA indireto quanto a reação de populações de melancia (Citrullus lanatus e Citrullus lanatus var. citroides) ao Papaya ringspot virus type watermelon (PRSV-W). UFERSA, Mossoró (RN), 2008.

\begin{tabular}{lcrrrr}
\hline \hline Modelos & $\begin{array}{c}\text { Graus de } \\
\text { liberdade }\end{array}$ & \multicolumn{2}{c}{ Nota dos Sintoma } & \multicolumn{2}{c}{$\begin{array}{c}\text { Sorologia em ELISA } \\
\text { indireto (Absorbância) }\end{array}$} \\
\cline { 2 - 6 } & & \multicolumn{1}{c}{$\mathbf{X}^{\mathbf{2}}$} & \multicolumn{1}{c}{ Prob. } & \multicolumn{1}{c}{$\mathbf{X}^{\mathbf{2}}$} & \multicolumn{1}{c}{ Prob. } \\
\hline \hline 1 vs. 2 & 3 & 61,6070 & 0,000000 & 35,0554 & 0,000000 \\
1 vs. 3 & 1 & 85,8631 & 0,000000 & 28,5028 & 0,000000 \\
1 vs. 4 & 4 & 193,4392 & 0,000000 & 112,2909 & 0,000000 \\
1 vs. 5 & 2 & 133,8519 & 0,000000 & 46,4059 & 0,000000 \\
1 vs. 6 & 5 & 207,2042 & 0,000000 & 112,5838 & 0,000000 \\
1 vs. 7 & 5 & 133,8513 & 0,000000 & 97,9098 & 0,000000 \\
1 vs. 8 & 6 & 204,6792 & 0,000000 & 116,0553 & 0,000000 \\
1 vs. 9 & 7 & 294,4285 & 0,000001 & 244,0103 & 0,000000 \\
2 vs. 4 & 1 & 131,8322 & 0,000000 & 77,2355 & 0,000000 \\
2 vs. 6 & 2 & 145,5972 & 0,000000 & 77,5284 & 0,000000 \\
2 vs. 7 & 2 & 72,2444 & 0,000000 & 62,8544 & 0,000000 \\
2 vs. 8 & 3 & 143,0722 & 0,000000 & 80,9999 & 0,000000 \\
2 vs. 9 & 4 & 232,8215 & 0,000000 & 208,9549 & 0,000000 \\
3 vs. 5 & 1 & 47,9888 & 0,000000 & 17,9031 & 0,000023 \\
3 vs. 6 & 4 & 121,3411 & 0,000000 & 84,0810 & 0,000000 \\
3 vs. 8 & 5 & 118,8161 & 0,000000 & 87,5525 & 0,000000 \\
3 vs. 9 & 6 & 208,5654 & 0,000000 & 215,5075 & 0,000000 \\
4 vs. 6 & 1 & 13,7649 & 0,000207 & 0,2928 & 0,588374 \\
4 vs. 8 & 2 & 11,2399 & 0,003624 & 3,7644 & 0,152255 \\
4 vs. 9 & 3 & 100,9893 & 0,000000 & 131,7194 & 0,000000 \\
5 vs. 6 & 3 & 73,3523 & 0,000000 & 66,1779 & 0,000000 \\
5 vs. 9 & 5 & 160,5766 & 0,000000 & 197,6044 & 0,000000 \\
6 vs. 9 & 2 & 87,2244 & 0,000000 & 131,4265 & 0,000000 \\
7 vs. 8 & 1 & 70,8278 & 0,000000 & 18,14553 & 0,000020 \\
7 vs. 9 & 2 & 160,5772 & 0,000000 & 146,1005 & 0,000000 \\
8 vs. 9 & 1 & 61,6070 & 0,000000 & 35,0554 & 0,000000 \\
\hline \hline
\end{tabular}


Desse modo, o modelo mais adequado para explicar a herança da resistência a PRSV-W em L26 é aquele que considera a existência de um gene maior com efeitos aditivos e não aditivo, juntamente com poligenes. Porém, essa metodologia não testa a existência de mais de um gene maior.

\section{CONCLUSÃO}

A resistência a PRSV-W na linha de melancia L26 é do tipo oligogênica.

\section{AGRADECIMENTOS}

Os autores agradecem ao Prodetab pelo financiamento do projeto, a Capes, pela concessão de bolsa de doutorado ao primeiro autor, ao CNPQ, pela concessão de bolsa de IC ao quinto e sexto autores, e a UFERSA, UNEB/DTCS e a UFC por disponibilizarem suas dependências para execução deste trabalho.

\section{REFERÊNCIAS}

AZEVEDO, S. M. et al. Inheritance of resistance to the papaya ringspot virus-watermelon strain (PRSVW) from watermelon accession 'PI 595201'4. Crop Breeding and Applied Biotechnology, Viçosa, v. 12, n. 1, p. 67-75, 2012.

BERNADO, R. Breeding for Quantitative traits loci in plants. Woodbury: Stemma Press. 2000. 369 p.

BESERRA JÚNIOR, J. E. A. et al. Herança da resistência ao Watermelon mosaic virus em melancia (C. lanantus L.). Fitopatologia Brasileira, Brasília, v. 32 , n. 3 , p. $302-305,2006$

BESERRA JÚNIOR, J. E. A.; FIGUEIRA, A. R.; MALUF, W. R. Seleção de linhagens de melancia resistentes ao watermelon mosaic virus e ao papaya ringspot vírus. Ciência e Agrotecnologia, Lavras, v. 31, n. 5, p. 1563-1568, 2007.

COSTA, C. P.; PINTO, C. A. B. P. Melhoramento de hortaliças. 2. ed. Piracicaba: Escola Superior de Agricultura "Luiz de Queiroz", Universidade do Estado de São Paulo, Piracicaba, 1977. 319 p.

CRUZ, C. D.; REGAZZI, A. J.; CARNEIRO, P. C. S. Biometrical Models Applied to Genetic Improvement. Viçosa: UFV. 2004. 480 p.

CRUZ, C. D. Programa Genes: biometria. Viçosa: UFV. 2006. 382 p.
DANIN-POLEG, Y. et al. Oligogenic inheritance of resistance to zucchini yellow mosaic virus in melons. Euphytica, New York, v. 93, n. 3, p. 331-337, 1997.

GILBERT, R.Z.; KYLE, M. M.; MUNGER, H. M. Inheritance of resistance watermelon mosaic virus in Cucumis melo L. HortScience, Alexandria, v. 29, n. 2, p. 107-194, 1994.

HULL, R. Matthew's Plant Virology. New York: Elsevier Academic Press. 2002.1001 p.

LE ROMANCER, M.; NEDELLEC, M. Effect of plant genotype, virus isolate and temperature on the expression of the potato tuber necrotic ringspot disease (PTNRD). Plant Pathology, Malden, v. 46, n 1, p. 104-117, 1997.

OLIVEIRA, A. C. B. et al. Resistance to papaya ringspot virus in Cucurbita pepo $\mathrm{L}$. introgressed from a interspecific $C$. pepo x C. moschata cross. Euphytica, New York, v. 132, n. 2, p. 211-215, 2003.

OLIVEIRA, V. B.; QUEIRÓZ, M. A,; LIMA, A. A. Fontes de resistência aos principais potyvirus isolados de cucurbitáceas no Nordeste brasileiro. Horticultura Brasileira, Brasília, v. 20, n. 4, p. 589-592, 2002.

OLIVEIRA, V. B. et al. Caracterização biológica e sorológica de isolados de potyvirus obtidos de cucurbitáceas no Nordeste brasileiro. Fitopatologia Brasileira, Brasília, v. 25, n. 4, p. 628-636, 2000.

OLIVEIRA, A. C. B. et al. Resistance to papaya ringspot virus in summer squash Cucurbita pepo introgressed from an interspecific C. pepo x C. moschata cross. Euphytica, New York, v. 132, n. 2, p. 211-215, 2003.

PROVVIDENTI, R.; ROBINSON, R. W. Inheritance of resistance to watermelon mosaic virus 1 in Cucumis metuliferus. Journal of Heredity, New York, v. 68, n. 1, p. 56-57, 1977.

PROVVIDENTI, R. Inheritance of resistance to the Florida strain of zucchini yellow mosaic virus in watermelon. HostScience, Alexandria, v. 26, n. 4, p. 407-408, 1991.

SHUKLA, D. D.; WARD, C. W.; BRUNT, A. A The Potyviridade. Cambridge. 1994. 516 p.

SILVA, W. P. Estimadores de máxima verossimilhança em misturas de densidades normais: Uma aplicação em genética. 2003. 60 f. Dissertação (Mestrado em Agronomia: área de concentração em Estatística e Experimentação) - Universidade Federal 
de Lavras, Lavras, 2003.

SITTOLIN, I. M.; PAVAN, M. A.; SILVA, N. Herança da tolerância de melancia aos vírus do mosaico amarelo da abobrinha-de-moita e do mosaico da melancia-2. Summa Phytophalogica, Botucatu, v. 26, n. 2, p. 210-214, 2000.

STRANGE, E. B. et al. Screening the Watermelon Germplasm Collection for Resistance to Papaya Ringspot Virus Type-W. Crop Science, Madison, v. 42, n. 4, p. 1324-1330, 2002.

SVOBODA, J.; POLÁK, J. Preliminary evaluation of squash cultivars for resistance to a Czech isolate of zucchini yellow mosaic virus. Progress in Cucurbit Genetics and Breeding Research, Olomouc, v. 8, n. 8, p. 231-235, 2004.

VIEIRA, J. V.; ÁVILA, C.; SILVA, G. O. Avaliação de genótipos de melancia para resistência ao Papaya ringspot virus, estirpe melancia. Horticultura Brasileira, Brasília, v. 28, n. 1, p. 7-11, 2010.

WAI, G.; GRUMET, R. Inheritance of resistance to the watermelon strain of papaya ringspot virus in Cucumber line TMG-1. HortScience, Alexandria, v. 30, n. 2, p. 338-340, 1995.

WANG, Y.J.; PROVVIDENTI, R.; ROBINSON, R.W. Inheritance of resistance to Watermelon mosaic virus 1 in cucumber. HortScience, , Alexandria, v. 19, n. 4, p. 587-588, 1984.

WEBB, R. E. Inheritance of resistance to watermelon mosaic virus 1 in Cucumis melo L. HortScience, Alexandria, v. 14, n. 3, p. 265-266, 1979.

$\mathrm{XU}, \mathrm{Y}$. Inheritance of resistance to zucchini yellow mosaic virus and watermelon mosaic virus in watermelon. Journal of Heredity, New York, v. 95, n. 6, p. 498-502, 2004. 